\title{
Chronicles of a primary care practice pharmacist
}

This article was published in the following Dove Press journal:

Integrated Pharmacy Research and Practice

16 November 2012

Number of times this article has been viewed

\author{
Christopher R Freeman' \\ W Neil Cottrell' \\ Greg Kyle ${ }^{2}$ \\ lan D Williams ${ }^{3}$ \\ Lisa M Nissen' \\ 'School of Pharmacy, University \\ of Queensland, Brisbane, Australia; \\ ${ }^{2}$ Faculty of Health, University \\ of Canberra, Canberra, Australia; \\ ${ }^{3}$ Camp Hill Healthcare, Camp Hill, \\ Brisbane, Australia
}

Background: In 2009, a pharmacist commenced working in a nondispensing role at a primary care medical center located in a metropolitan suburb of Brisbane, Australia. Research into the role and function of a practice pharmacist in this setting is still in its infancy.

Methods: Ethnographic methods were used over a 3-month period to record activities undertaken by the practice pharmacist on a daily basis.

Results: During the 3-month period, 296 hours of activity were documented. Activities the practice pharmacist performed most frequently included medication review, "pharmaceutical opinion," student supervision, drug information, and administrative tasks.

Conclusion: This study demonstrates the broad range of activities which were conducted by a practice pharmacist in the primary care setting as part of a multidisciplinary team.

Keywords: practice pharmacist, general practice, integration, medical center

\section{Background}

In April 2009, a pharmacist (CF) commenced working in a nondispensing role at a primary care medical center located in a metropolitan suburb of Brisbane, Australia. The medical center is considered large, with 16 full- and part-time general practitioners (GPs), as well as nursing and allied health professionals, spread across two buildings. The practice pharmacist's initial responsibility was to conduct medication reviews (known as the Home Medicines Review program in Australia) for patients of the practice. A consultation room was provided for the practice pharmacist, who also had access to the patients' electronic health records.

Over the course of 2.5 years, the role of the practice pharmacist expanded from the sole provision of medication reviews to a variety of professionally based services. Research from Canada, USA, and the United Kingdom reports pharmacists working in this setting conduct a number of roles including medication review, education, academic detailing, medication reconciliation, general practice preceptor, disease focused clinics, formulary development, and system level activities such as quality prescribing activities (prescribing audits). ${ }^{1-8}$ Outcomes to date have indicated that a "practice pharmacist" may improve clinical indicator monitoring, improve disease management, detect potential medication misadventure, improve treatment plan implementation, and reduce health costs. ${ }^{1,6,9,10}$

Research exploring the opinions of GPs, pharmacists, and health care consumers has identified potential roles for the practice pharmacist in the Australian setting. ${ }^{11,12}$ Roles that were viewed positively by the stakeholders included direct patient contact roles such as medication review, patient counseling on medication use, and the 
potential to prescribe medications in a collaborative fashion. Non-direct patient contact roles were also identified, and included activities such as conducting medication use evaluation and education, and providing drug information to health professionals on staff. These roles reflect both the international literature as well as present roles conducted by pharmacists (apart from prescribing) in Australia outside of the general practice medical center setting. Despite this, research into the day to day role and function of a practice pharmacist is still in its infancy, particularly in Australia. ${ }^{13}$

The aim of this project was to provide an account of the activities carried out by a primary care practice pharmacist on a day-to-day basis.

\section{Methods}

An exploratory project using an ethnographic approach was adopted to describe the daily activities conducted by a pharmacist in the primary care practice setting. The practice pharmacist kept a diary over a 3-month period (May 2011 to July 2011) to provide an in-depth description of everyday activities that were undertaken. In the diary, the practice pharmacist recorded the type of activity, the time taken to conduct the activity, with additional notes thought to be relevant. The practice pharmacist also made reflective narrative entries with a focus on observations and interactions during the day.

To analyze the type of activities conducted, an evolving coding system was used. When a new activity was identified, it was given an identity code and added to the coding list. Activities with the same code were then sorted and interrogated for the time spent on the activity. Additional notes that accompanied the activity entry were used to provide a description of the activity. The coded data from the diary was stored and analyzed in a Microsoft Excel (Microsoft Corporation, Redmond, WA) spreadsheet.

Content analysis was conducted to interpret the reflective entries made by the practice pharmacist. From this, interpreter-driven themes were derived and applied to the entries. Given the small number of reflective entries (18), each was given a theme, with similar themes grouped together.

This study was approved by the Human Research Ethics Committee of the University of Queensland, in accordance with the National Health and Medical Research Council's guidelines (approval number 2011/6).

\section{Results}

The practice pharmacist worked at the medical center 3.5 days a week. During the 3-month period, 296 hours of activity was documented. Figure 1 illustrates the types of activities performed by the practice pharmacist and the proportion of time spent on each activity.

In total, the practice pharmacist made 18 reflective entries, which were related to three themes: access to the patients' medical files, increased opportunity for communication, and acceptance as a valued member of the general practice team. The three most frequently conducted activities by the practice pharmacist included medication review, pharmaceutical opinion, and student supervision.

Patients attending the medical center were identified for a medication review by either their GP or the community nurse. The consultation between the practice pharmacist and the patient was usually conducted in the patient's place of

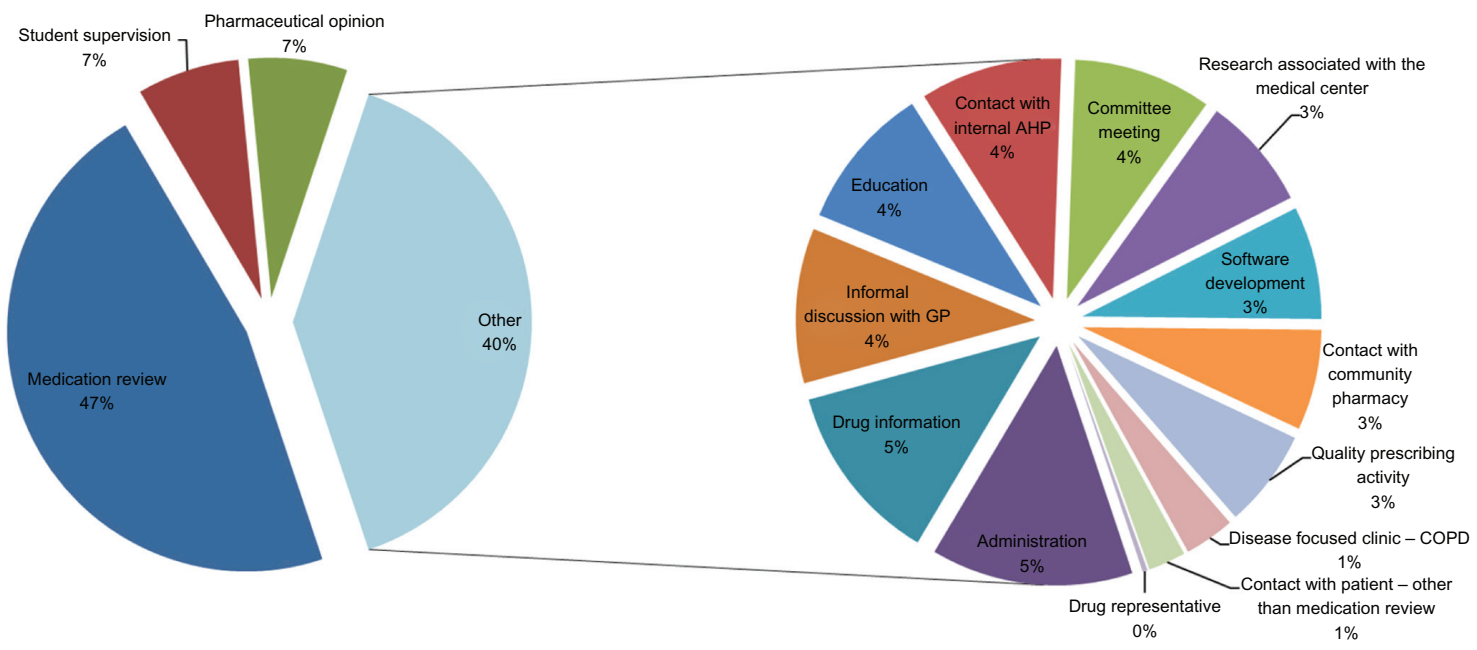

Figure I Roles performed by the practice pharmacist and the proportion of time spent on each activity (\%).

Abbreviations: AHP, allied health professionals; GP, general practitioner; COPD, chronic obstructive pulmonary disease. 
residence; however, it could also be conducted in the medical center under extenuating circumstances. During the medication review, the practice pharmacist interviewed the patient and reviewed his or her medications to identify drug related problems, or issues the patient reported experiencing with his or her medicines; the practice pharmacist also reviewed the patient's adherence to his or her medication. Examples of drug related problems included the requirement of additional therapy, the presence of an adverse drug reaction, and identification of suboptimal therapy. ${ }^{14}$

The overall aim was to achieve the safe, effective, and appropriate use of medications through detecting and addressing medication related problems that may interfere with desired health outcomes. Once the medication review was completed by the practice pharmacist, a report was uploaded directly into the medical software with an alert sent electronically to the GP. A copy of the report was also sent to the patient's community pharmacy (or pharmacies). The practice pharmacist took opportune times (such as in between patient consultations) to discuss the medication review with the GP, practice nurse, and other relevant allied health staff associated with the medical center.

The ability to access the patient's medical file was repeatedly mentioned in the reflective entries, and it was generally related to conducting medication reviews or providing "pharmaceutical opinion" services:

Having access to the patient's notes is so useful; I don't know how I worked without them previously. I can view pathology, specialist letters; I can even go back and see which medications have been trialed in the past.

The practice pharmacist acknowledged that integration provided an enhanced opportunity for GP contact:

I find myself planning to have lunch at the same time as particular GPs which gives me an opportunity to catch up with them. We may discuss particular patients or medication use in a general sense. I feel this has helped increase my rapport with the GPs and also increased the number of medication review referrals I receive.

Feeling like a part of a team and the value placed on the practice pharmacist by the GPs was also recorded:

The GPs provide me with such positive feedback; today one of the female GPs mistakenly thought I was leaving the clinic. She said, "I wouldn't know what to do without you here!" They really value the input I have on the care of their patients.
Working in the medical center reminds me of my time spent practicing in the hospital setting - I really feel a part of the team, all working together in a coordinated fashion to improve the health of the patient.

"Pharmaceutical opinion" was a term used to describe an activity in which the practice pharmacist would supply advice on therapeutic management for a particular patient. This was not recorded as a medication review, as it was not a comprehensive review of the patient's medication management, and it usually did not involve direct patient contact. Additionally, it was not recorded as a drug information request, as it required the practice pharmacist to apply therapeutic decision-making skills regarding a particular patient, while considering any comorbidities and concurrent medications. Drug information for the purpose of this project was more general in nature and less patient-focused. Typically, information exchange between the GP and practice pharmacist occurred through internal email or by telephone; however, it occasionally involved the practice pharmacist joining the GP-patient consultation. The following typifies a "pharmaceutical opinion" request by a GP:

I am about to see a patient who I have trialed sertraline and venlafaxine for her menopausal night sweats. We have had no luck with either. Would you mind having a look in her medical file and providing me with your recommendation?

During the 3-month period, almost 21 hours (7\%) was spent providing supervision to pharmacy, medicine, and nursing students while on experiential placements. Students would shadow the practice pharmacist during medication reviews, and they would actively participate by interviewing the patients regarding their medication use, and by performing assessments and observations (including blood pressure and pulse monitoring). The students were also given the opportunity to provide focused education to the patient surrounding medication or disease state management. After the medication review, the practice pharmacist and student would spend time discussing the patient - in particular, the drug-related problems identified and the potential solutions offered for the identified problems.

Other activities that were observed, which required a smaller amount of time, included providing educational sessions (for GPs, allied health professionals, and nurses), attending internal committee meetings (such as quality improvement team meetings), engaging in quality prescribing activity (a prescribing audit), attending a disease-focused clinic (for instance, a chronic obstructive pulmonary disease 
clinic involving a GP, a nurse, and a practice pharmacist), having informal discussions with the GPs (such as in the lunchroom), and providing drug information. The medical center was also involved in the development of medical software, and during the project period, the practice pharmacist was tasked with providing advice on medication, and also mapping medications to their respective classes. The practice pharmacist acted as a liaison between the surrounding community pharmacies and the medical center on technical areas such as prescription clarification or commencing a dose administration aid, and the practice pharmacist was also involved in clinical areas by supplying patient medical information (with the patient's consent).

\section{Discussion}

The results of this explorative project have demonstrated a range of roles which a pharmacist integrated into a general practice environment may conduct. The roles identified in this study closely align with pharmacist services available in Australia that are external to the medical center setting; however, they are also enhanced via integration. Further, new roles for the practice pharmacist arose due to the presence of the pharmacist being physically located in the medical center.

The narrative entries by the practice pharmacist indicate that there are some benefits to practicing in an integrated setting compared to practicing externally to the medical center. These include access to the patient's electronic medical file, and a greater feeling of being part of a team. The increased opportunity for informal communication between health professionals, in particular between the practice pharmacist and GPs, was also highlighted as a benefit. The informal discussions occurred passing in the hallway, sitting in the lunchroom, or in between patients, and covered a variety of pharmaceutical topics. Despite the informal nature of this type of communication, the impact should not be underestimated. ${ }^{15}$ The benefits described in this project closely align with research investigating the opinions of key stakeholders indicating that the proposed benefit of integration is realized. ${ }^{12}$

It was not surprising to find that medication review was the primary function of the practice pharmacist. Medication review is currently the only cognitive service conducted by a pharmacist, which is renumerated by the Australian government outside the community pharmacy setting. For the role of the pharmacist in a primary care medical center to be financially sustainable, it was necessary that a large proportion of time was spent conducting medication reviews.
Traditionally, medication reviews in Australia are conducted without access to the patient's medical files. As described in a reflective entry made by the practice pharmacist, the ability to access the patient medical file was viewed as invaluable. The medical file gave the practice pharmacist the ability to view the patient's past medical history, pathology, specialist correspondence, and previously trialed medications, all of which are important when providing pharmaceutical care. The international literature also describes medication review as a primary and suitable role for the practice pharmacist. ${ }^{1,2,16}$

Farrell et $\mathrm{al}^{8}$ used case studies to describe two typologies that signify the role of the practice pharmacist in Ontario, Canada. The first case study highlighted a practice pharmacist with a physician focus, responding to physician enquires and requests for drug information and projects. The practice pharmacist did not spend a significant amount of time at the medical center and had little to no direct patient contact. The second case study reported a practice pharmacist that carried out roles that closely reflected the style of practice described in our findings. The practice pharmacist had a variety of roles with direct patient contact, providing education and information, and system level activities aimed at improving quality use of medicines. Further, the practice pharmacist was physically located at the medical center for the majority of the time. It was this second case study that most closely aligns with the roles reported in our study, and which appeared to be most successful in the Farrell et al study.

Many of the roles described in this project, beyond that of medication review, have also been reported in the international literature. These include drug information/ pharmaceutical opinion, ${ }^{3,8}$ education, ${ }^{1,2,7}$ and system-level activities. ${ }^{1,9,17}$ This indicates that, despite the differences in health care systems across these countries, the role and core function of a practice pharmacist are similar.

It is important to realize that many of the services, in addition to the medication reviews offered by the practice pharmacist, were tailored to meet the needs of both the medical center and the surrounding community. This was illustrated by the breadth of services performed including student supervision, software development, and the chronic obstructive airways disease clinic.

Investigation into the opinions of GPs, pharmacists, and health care consumers from Australia on pharmacist integration into a medical center have been reported, and included potential roles for the practice pharmacist. ${ }^{11,12}$ Roles which were viewed positively by the participants included medication review, education, drug information, specialty clinics, and system level activities such as medication 
use evaluation. ${ }^{11,12}$ These closely align with our results demonstrating many of the roles the participants indicated can be translated into practice.

There are some roles detailed in the literature which were either identified as being a potential role, or were roles that were currently being provided by a practice pharmacist that did not eventuate in this study. Pharmacist prescribing has been identified in the Australian research and has been realized in international research as a role for the practice pharmacist. ${ }^{11,12,18-20}$ Presently in Australia, pharmacists do not have the authority to prescribe, and hence this activity was absent in our study; however, this activity could be the focus of future research pending legislative changes.

There has been much documented on the risks surrounding medication management when patients are transferred from primary to tertiary care, or vice versa. ${ }^{21}$ Gray et $\mathrm{al}^{10}$ found that patients in the UK were more likely to receive the treatment plan recommended at hospital discharge if the practice pharmacist was copied on the discharge summary. Practice pharmacists may play an important role with respect to medication management when patients are discharged from the hospital; this is also an equally important role when patients are being admitted to hospital, as practice pharmacists can engage in medication reconciliation.

This study has three main limitations. First, the study only involved one pharmacist practicing at one medical center. Some of the roles may have eventuated given the individual pharmacist's skills and training, or the individual characteristics of the medical center. However, given the similarity of our results to the international literature and to local research on stakeholder opinions, our results appear valid. Second, the short time frame of data collection may have limited the scope of services recorded and may have potentially missed services which occur sporadically, such as protocol development or review. Third, only one of the authors was involved in coding both the roles and the reflective entries of the practice pharmacist, which may potentially limit the interpretation of the results.

\section{Conclusion}

This study presents narrative reports on the broad range of activities that were conducted by a practice pharmacist in the primary care setting as part of a multidisciplinary team. This project may serve as a pilot to a larger study, which would aim to evaluate not only the role of the pharmacist in this setting, but also to determine how effective the pharmacists are in this role.

\section{Acknowledgment}

The authors would like to acknowledge the members of the Quality Use of medicines work In Progress (QUIP) group at the School of Pharmacy, University of Queensland for their valued input.

\section{Disclosure}

The authors report no conflicts of interest in this work.

\section{References}

1. Dolovich L, Pottie K, Kaczorowski J, et al. Integrating family medicine and pharmacy to advance primary care therapeutics. Clin Pharmacol Ther. 2008;83(6):913-917.

2. Fish A, Watson MC, Bond CM. Practice-based pharmaceutical services: a systematic review. Int J Pharm Pract. 2002;10(4):225-233.

3. Ables AZ, Baughman OL 3rd. The clinical pharmacist as a preceptor in a family practice residency training program. Fam Med. 2002;34(9):658-662.

4. Cone SM, Brown MC, Stambaugh RL. Characteristics of ambulatory care clinics and pharmacists in Veterans Affairs medical centers: an update. Am J Health Syst Pharm. 2008;65(7):631-635.

5. Martin RM, Lunec SG, Rink E. UK postal survey of pharmacists working with general practices on prescribing issues: characteristics, roles and working arrangements. Int J Pharm Pract. 1998;6(3): 133-139.

6. Carter BL, Malone DC, Billups SJ, et al; for Impact of Managed Pharmaceutical care on resource utilization and Outcomes in Veterans affairs medical centers. Interpreting the findings of the IMPROVE study. Am J Health Syst Pharm. 2001;58(14):1330-1337.

7. Lowe CJ, Raynor DK, Purvis J, Farrin A, Hudson J. Effects of a medicine review and education programme for older people in general practice. Br J Clin Pharmacol. 2000;50(2):172-175.

8. Farrell B, Ward N, Dore N, Russell G, Geneau R, Evans S. Working in interprofessional primary health care teams: What do pharmacists do? Res Social Adm Pharm. In press 2012.

9. Avery AJ, Rodgers S, Cantrill JA, et al. A pharmacist-led information technology intervention for medication errors (PINCER): a multicentre, cluster randomised, controlled trial and cost-effectiveness analysis. Lancet. 2012;379(9823):1310-1319.

10. Gray S, Urwin M, Woolfrey S, Harrington B, Cox J. Copying hospital discharge summaries to practice pharmacists: does this help implement treatment plans? Qual Prim Care. 2008;16(5):327-334.

11. Freeman C, Cottrell WN, Kyle G, Williams ID, Nissen L. Pharmacists', general practitioners' and consumers' views on integrating pharmacists into general practice. J Pharm Pract Res. 2012;42(3):184-188.

12. Freeman C, Cottrell WN, Kyle G, Williams I, Nissen L. Integrating a pharmacist into the general practice environment: opinions of pharmacist's, general practitioner's, health care consumer's, and practice manager's. BMC Health Serv Res. 2012;12(1):229.

13. Ackermann E, Williams ID, Freeman C. Pharmacists in general practicea proposed role in the multidisciplinary team. Aust Fam Physician. 2010;39(3):163-164.

14. Freeman CR, Cottrell WN, Kyle G, Williams ID, Nissen L. An evaluation of medication review reports across different settings. Int $J$ Clin Pharm. In press 2012.

15. Brown JB, Lewis L, Ellis K, Stewart M, Freeman TR, Kasperski MJ. Mechanisms for communicating within primary health care teams. Can Fam Physician. 2009;55(12):1216-1222.

16. Altavela JL, Jones MK, Ritter M. A prospective trial of a clinical pharmacy intervention in a primary care practice in a capitated payment system. J Manag Care Pharm. 2008;14(9):831-843. 
17. Devine EB, Hoang S, Fisk AW, Wilson-Norton JL, Lawless NM, Louie C. Strategies to optimize medication use in the physician group practice: the role of the clinical pharmacist. JAm Pharm Assoc (2003). 2009;49(2):181-191.

18. Alsuwaidan S, Malone DC, Billups SJ, Carter BL. Characteristics of ambulatory care clinics and pharmacists in Veterans Affairs medical centers. IMPROVE investigators. Impact of Managed Pharmaceutical Care on Resource Utilization and Outcomes in Veterans Affairs Medical Centers. Am J Health Syst Pharm. 1998;55(1):68-72.

19. Guillaume L, Cooper R, Avery A, et al. Supplementary prescribing by community and primary care pharmacists: an analysis of PACT data, 2004-2006. J Clin Pharm Ther. 2008;33(1):11-16.
20. Stewart DC, MacLure K, Bond CM, et al. Pharmacist prescribing in primary care: the views of patients across Great Britain who had experienced the service. Int J Pharm Pract. 2011;19(5):328-332.

21. Easton K, Morgan T, Williamson M. Medication Safety in the Community: A Review of the Literature. Sydney, Australia: National Prescribing Service; 2009. Available from: http://www.nps.org.au/_data/ assets/pdf_file/0008/71675/09060902_Meds_safety_June_2009.pdf. Accessed May 29, 2012.

\section{Publish your work in this journal}

Integrated Pharmacy Research and Practice is an international, peer-reviewed, open access, online journal, publishing original research, reports, reviews and commentaries on all areas of academic and professional pharmacy practice. This journal aims to represent the academic output of pharmacists and pharmacy practice with particular focus on integrated care. All papers are carefully peer reviewed

Submit your manuscript here: http://www.dovepress.com/integrated-pharmacy-research-and-practice-journal to ensure the highest standards as well as ensuring that we are informing and stimulating pharmaceutical professionals. The manuscript management system is completely online and includes a very quick and fair peer-review system, which is all easy to use. Visit http://www.dovepress.com/testimonials.php to read real quotes from published authors. 